\title{
INNOVACIÓN Y TRADICIÓN EN LAS MENTIRAS CRETENSES DE ODISEO (CANTOS 13-19)
}

\author{
Caterina Anush Stripeikis* \\ Recebido em: 23/04/2018 \\ Aprovado em: 12/06/2018
}

RESUMEN: El objetivo de este trabajo consiste en analizar los relatos cretenses de Odiseo bajo las siguientes premisas: en ellos se puede percibir la existencia de una Odisea alternativa, compuesta por un grupo de versiones épicas del nóstos del héroe en el que Creta jugaba un rol central. No obstante, el poeta individual de la Odisea homérica opera activamente sobre esta tradición alternativa, modificándola. Así, se analizarán los mecanismos compositivos mediante los que el poeta individual realiza esta operación, tomando en cuenta no solo la presencia de un auditorio interno, sino también de la audiencia frente a la que se ejecutaba la performance. Se espera constatar que los estratos orales pertenecientes a una Odisea alternativa no ingresan como un mero Zitat a la Odisea homérica, sino que lo hacen modificados activamente por la voluntad del poeta.

PALAVRAS CLAVE: Odisea; Creta; mentiras; innovación; tradición.

\section{INNOVATION AND TRADITION IN ODYSSEUS' CRETAN LIES (BOOKS 13-19)}

* Licenciada y Profesora en Letras con orientación en Letras Clásicas, Universidad de Buenos Aires, Facultad de Filosofía y Letras, Instituto de Filología Clásica. caterina.stripeikis@ gmail.com

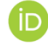

\begin{abstract}
The aim of this work consists in analyzing the Cretan tales of Odysseus under the following premises: in these tales the existence of an alternative Odyssey comprised of a group of epic versions about the hero's nostos in which Crete played a major role can be perceived. Nevertheless, the individual poet of the Homeric Odyssey actively modifies this alternative tradition. Therefore, the compositional mechanisms through which the individual poet effects this modification will be analyzed, taking into account not only an internal audience but also the audience that witnessed the performance. I expect to verify that the oral strata belonging to an alternative Odyssey are not incorporated in the Homeric Odyssey as a mere Zitat. Quite the contrary, they appear actively modified by the will of the poet.
\end{abstract}

KEYWORDS: Odyssey; Crete; lies; innovation; tradition. 


\section{INTRODUCCIÓN}

$\mathrm{D}$ esde las investigaciones conducidas por Milman Parry, la composición de la Ilíada y la Odisea ha sido en numerosas ocasiones atribuida a un poeta 'tradicional', es decir, a un poeta que, como vehículo de una tradición, repite fórmulas heredadas de sus predecesores en el entramado compositivo de estos poemas. ${ }^{1}$ A partir de esta circunstancia, los partidarios más radicales de la teoría de Parry han llegado a afirmar que la poesía homérica es cien por ciento de carácter formulaico. ${ }^{2}$ Afirmaciones de este talante han sido puestas en entredicho por Finkelberg (2012: 73-82), quien establece que no hay evidencia suficiente para afirmar un carácter formulaico absoluto de la dicción homérica. Muy por el contrario, esta autora percibe en el sistema formulaico de los poemas homéricos "quite a few breaches in formulaic economy due to the poet's intention to express something for which his tradition has provided no ready made solution" (Finkelberg, 2012: 81). Bajo la perspectiva esbozada por esta crítica, el poeta no actuaría solo como un receptor y mediador pasivo de una tradición, sino que operaría conscientemente sobre ella conforme a sus deseos e intenciones compositivas. Es decir, pasaría de ser un poeta 'tradicional' a ser un poeta 'individual'.

Un razonamiento semejante al propuesto por Finkelberg puede llegar a aplicarse en el caso de las mentiras cretenses de Odiseo. Estos relatos se encuentran distribuidos a lo largo de la segunda parte de la Odisea (13. 256-286; 14. 192-352; 17. 419-444; ${ }^{3} 19.165-$ 202, 221-248, 262-303) y son empleados por el héroe para ocultar su identidad frente a los distintos personajes con los que se encuentra.

Como sucede con la mayoría de los tópicos estudiados por los homeristas, el análisis de las mentiras cretenses de Odiseo ha sido encarado desde múltiples posicionamientos críticos. Se destacan dos posturas. Una afirma que en estos relatos se puede percibir la existencia de una Odisea alternativa, compuesta por un grupo de versiones épicas del nóstos del héroe en el que Creta jugaba un rol central. En este sentido, las mentiras cretenses no serían más que un extenso Zitat épico incorporado a la Odisea, una ventana intertextual a

\footnotetext{
${ }^{1}$ Cfr. Parry (1971). Una reflexión análoga puede aplicarse al concepto de tema (theme) en los poemas homéricos, puesto que un tema es entendido como una unidad de sujeto, un grupo de ideas empleadas regularmente por un bardo no sólo en cualquier poema sino en toda la tradición poética (Lord 1938:440). Así, el tema constituye un bloque narrativo recurrente con una estructura identificable (e.g. un sacrificio, la recepción de un huésped, entre otros).

${ }^{2}$ Cfr. especialmente Lord (1960; 1991) y Notopoulos (1964). Para profundizar en los desarrollos de la teoría oral desde los trabajos de Parry, consúltese Nagy (1979; 1996) y Foley $(1988 ; 1990 ; 1999$, entre otros).

${ }^{3}$ Estrictamente hablando no hay una mención de Creta en estos versos. No obstante, se toman en consideración para el análisis debido a que exhiben uno de los motivos recurrentes en las otras narraciones (la batalla en Egipto) y a que resultan particularmente importantes para una consideración del modo en el que el poeta individual adecua sus relatos a las distintas audiencias internas (cfr. 3.4).
} 
una tradición oral alternativa del regreso de Odiseo (Tsagalis, 2012: 344). En otras palabras, dicha tradición oral constituiría la 'fórmula' que el poeta recibe y emplea en las secciones arriba enumeradas. La segunda postura aboga por una participación más activa del poeta en la configuración de los relatos cretenses y llega incluso a desestimar por completo la existencia de versiones alternativas de la Odisea. Los partidarios de esta postura afirman que la presencia de un poeta individual se constata a partir de los mecanismos que Odiseo emplea para adecuar cada una de las mentiras cretenses a su auditorio inmediato (e.g. Atenea, Eumeo, Penélope). ${ }^{5}$

El objetivo de este trabajo consiste en analizar los relatos cretenses de Odiseo bajo una premisa semejante a la establecida por Finkelberg (cfr. arriba) para la concepción de las fórmulas homéricas. Así, no se niega la existencia de una Odisea alternativa de marcada impronta cretense, sino su concepción como un mero Zitat incorporado a la Odisea homérica. En este sentido, se intentarán identificar los mecanismos compositivos mediante los que el poeta individual opera sobre la tradición oral de dicha Odisea, tomando en consideración no solo la presencia de un auditorio interno, sino también de la audiencia frente a la que se ejecutaba la performance.

\section{Los Hitos PRINCIPALES DE UNA ODISEA ALTERNATIVA}

Tsagalis (2012: 309-345) ofrece un minucioso análisis de los distintos estratos orales presentes en los relatos de Odiseo, que abarca desde el empleo de folk-tale motives hasta distintas versiones de un ciclo épico alternativo de nóstoi. Entre los elementos destacados por este autor, la presencia de una Odisea alternativa se constata de modo más fehaciente si se toman en consideración los siguientes motivos, repetidos en dos o más narraciones falsas de la Odisea homérica: Creta como patria de Odiseo; mención de Idomeneo; batalla en Egipto; presencia de fenicios y viaje a Tesprotia.

Tsagalis (2012: 314-319) justifica la ubicua presencia de Creta en una Odisea alternativa a partir de una serie de evidencias internas y externas. Se destacan dos, una de cada tipo. Como prueba interna, resulta bastante significativo el hecho de que Odiseo, en tanto narrador, enfatiza sistemáticamente su identidad cretense. ${ }^{6}$ A modo de justificativo externo, se pueden

\footnotetext{
${ }^{4}$ Para la existencia de una Odisea alternativa, cfr. también Woodhouse (1930), West (1981) y Reece (1994). Para el concepto de Zitat, ver Danek (1998).

${ }^{5}$ Uno de los representantes más importantes de esta postura es Trahman (1952). Cfr. asimismo, Emlyn-Jones (1986).

${ }^{6}$ Otros justificativos esbozados por Tsagalis son: a) la aseveración del proemio de la Odisea acerca de los vagabundeos del héroe resulta más coherente aplicada a los relatos falsos de Odiseo que a la Odisea homérica en sí; b) existe un significativo contraste entre la vaga noción topográfica del Peloponeso que exhibe el poeta de la Odisea homérica y su detallado conocimiento de la geografía cretense; c) Eumeo dice explícitamente en $\mathrm{Od}$. 14. 379-385 que un Etolio le ha dicho que ha visto a Odiseo en Creta, en el palacio de Idomeneo, reparando el daño de sus naves y que el héroe regresará a Ítaca junto con amigos y riquezas. A estas razones, Tsagalis agrega ciertas inconsistencias perceptibles en el momento
} 
aducir dos variantes recogidas por Zenódoto en los escolios a $O d$. 3.313 que sugieren que, tanto en $O d$. 1.93 como en $O d$. 1. 285, Atenea tenía intenciones de enviar a Telémaco a Creta para encontrarse con Idomeneo y no al palacio de Menelao en Esparta luego de su intercambio con Néstor. ${ }^{7}$ Con respecto a la recurrente presencia de Idomeneo, esta se podría explicar debido al hecho de que dicho personaje, conocido rey cretense, inevitablemente debería formar parte de una Odisea alternativa en la que el héroe y Telémaco visitaran Creta. ${ }^{8}$ Asimismo, la batalla en Egipto, la presencia fenicia y el viaje a Tesprotia exhiben ciertas características propias de la épica cíclica que convierten a estos acontecimientos en candidatos plausibles para integrar una alter-Odisea. En el caso de Egipto, Tsagalis (p. 335-337) destaca tres motivos presentes en el ciclo épico: "the $7+1$ year motif", atestiguado en los Nóstoi para la estancia de Menelao también en Egipto; "the motif of second departure", presente en la Telegonia; "the motif of being defeated in a foreign land", mencionado en los Cypria en el marco de la expedición a Teutrania y de la lucha contra Télefo. De igual modo, una variante del "7+1 year motif" aparece para caracterizar la estancia de Odiseo en Fenicia durante el relato referido a Eumeo (Od. 14. 292-294). Finalmente, el viaje a Tesprotia que figura en la Odisea homérica y los sucesos relacionados con él podrían provenir de dos tradiciones épicas alternativas, una de carácter más local (quizás el Thesprotis al que alude Pausanias, 8.12.5) y otra correspondiente a una Telegonía de impronta panhelénica (cfr. Tsagalis, p. 338-344).

\section{UNA ODISEA ALTERNATIVA Y EL POETA INDIVIDUAL}

\subsection{El personaje de Odiseo, la elección de Creta y la Audiencia externa}

El poeta de la Odisea ha empleado un material considerable de tradiciones alternativas en la configuración de los relatos cretenses. No obstante, este material ingresa allí bajo una impronta particular: la constante caracterización del hijo de Laertes como hábil mentiroso. Estos rasgos, quizás esbozados ligeramente en alguno de los episodios del ciclo épico, ${ }^{9}$ son enfatizados por el poeta de la Odisea homérica en el marco de los relatos cretenses. Así,

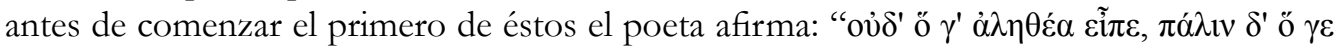

de la anagnórisis entre Telémaco y su padre (p. 317-318), mediante las que se podría corroborar un encuentro previo entre padre e hijo en Creta, y la presencia de dos 'Odiseos' a lo largo de los relatos cretenses, uno inclinado hacia el amor familiar y el poco interés por la guerra; otro interesado por las proezas militares y el lucro (p. 330).

${ }^{7} \mathrm{La}$ autenticidad de las variantes zenodoteas ha sido demostrada de manera fehaciente por West (1981). Otro de los motivos externos aducidos por Tsagalis (p. 315) es la existencia de una versión del regreso de Odiseo con una fuerte impronta cretense escrita por Dictys Cretensis.

${ }^{8}$ Contra Tsagalis (p. 325, n. 58) quien cree que este argumento no resulta lo suficientemente contundente y opta, en cambio, por justificar la presencia de Idomeneo solo a partir de elementos presentes en el ciclo épico.

${ }^{9}$ Un candidato plausible puede ser la Pequeña Ilíada, puesto que allí se narraba la entrada de Odiseo a la ciudad de Troya disfrazado de mendigo, su encuentro con Helena y el robo del Paladio. 


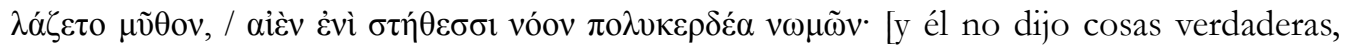
sino que otra vez contuvo el relato, siempre revolviendo en su pecho un pensamiento muy provechoso, $\mathrm{Od}$. 13. 254-255]. ${ }^{10}$ A su vez, luego de dicha narración, Atenea se dirige al héroe con las siguientes palabras:

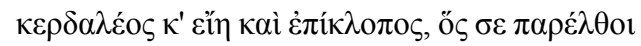

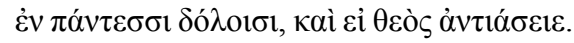

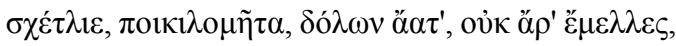

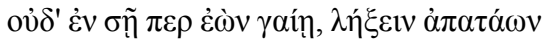

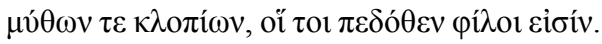

Sería ventajero e ingenioso el que te sobrepasara en todos los engaños, incluso si un dios le saliera al encuentro. ¡Cruel, de variada astucia, incansable en los engaños! No ibas, ni aún en tu tierra, a dejar los engaños y los relatos embusteros que te son profundamente queridos.

(Od. 13. 291-296).

Resulta significativo el empleo de un campo semántico afín para caracterizar

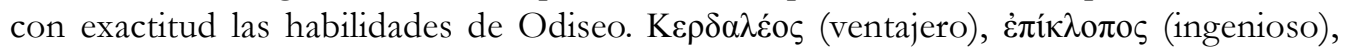

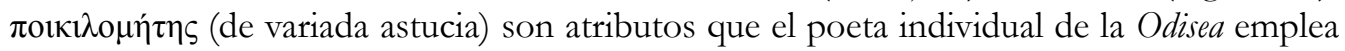
en su construcción de un perfil del héroe, construcción que pudo haber resultado decisiva para terminar de definir los rasgos fundamentales de Odiseo tal como fueron percibidos por los griegos de los siglos siguientes (y por los estudiosos actuales de los poemas homéricos).

En el caso del relato dirigido a Eumeo, el poeta va un paso más allá y se permite jugar con estos rasgos odiseicos para generar, acaso, una reacción particular en la audiencia de la performance. En 14. 363-365, Eumeo, quien ha creído sin asomo de duda toda la invención de Odiseo, pone reparos solo en una parte de su relato: la vuelta del hijo de Laertes sano y

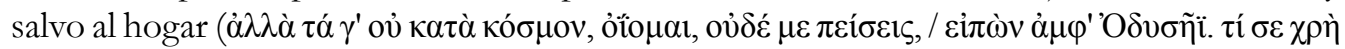

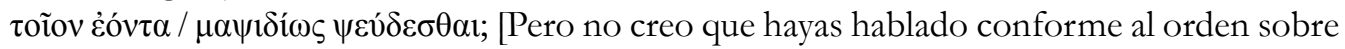
Odiseo ni me persuadirás. ¿Por qué te es necesario, siendo cual eres, mentir inútilmente?]). El regreso de Odiseo a Ítaca, la única parte verdadera de la fabulación dirigida a Eumeo, es, paradójicamente, la única que el porquerizo no cree. ${ }^{11}$ El poeta construye esta pequeña ironía a partir de un rasgo característico de Odiseo quizás con el objetivo de divertir a la audiencia, de incrementar su complicidad con el héroe y de aludir a las consecutivas anagnóríseis que desembocarán en el desenlace final del poema. En efecto, en ese momento de la narración, el auditorio de la performance comparte con Odiseo una información que Eumeo ignora por completo (e.g. su verdadera identidad), pero que espera sea revelada en breve. Asimismo, durante el transcurso de su intercambio con Penélope (19. 165-202, 221-248, 262-303), el

\footnotetext{
${ }^{10}$ La edición base es la de von der Mühll (1946) y las traducciones me pertenecen en todos los casos.

${ }^{11}$ Trahman (1952: 38); Emlyn Jones (1986: 11) y Richardson (1996: 396) mencionan esta circunstancia. No obstante, no la vinculan con las posibles reacciones de la audiencia de la performance homérica.
}

Classica, v. 31, n. 1, p. 25-42, 2018 


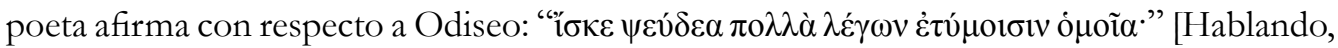
asemejaba muchas mentiras a realidades, v. 203]. ${ }^{12}$

Por último, la constante aparición de Creta como patria de Odiseo no es una circunstancia que el poeta haya meramente reproducido a partir de la existencia de una saga cretense alternativa. Muy por el contrario, su elección de esta saga podría deberse a una voluntad de despertar cierto imaginario relacionado con Creta compartido por la audiencia de la performance. Ya Eustacio en sus Parékbolai (2.196.26) esbozó como justificativo de la presencia de Creta en los relatos falsos de Odiseo el hecho de que los habitantes de esta isla tenían fama de mentirosos. ${ }^{13}$ En este sentido, la elección de Creta aparece como un rasgo que complementa hábilmente la caracterización del héroe en tanto fabulador frente al auditorio, posibilitando razonamientos del tipo "ya que el poeta caracteriza a Odiseo como un personaje engañoso, resulta muy oportuno que, en sus relatos falsos, sea oriundo de una tierra habitada por gente charlatana y mentirosa."

\subsection{Encuentro con Atenea}

La primera mentira cretense tiene lugar después de que Odiseo llega a Ítaca a bordo del barco feacio. Atenea ha cubierto los alrededores con una espesa niebla para que el héroe no reconozca dónde se encuentra. Frente a esta circunstancia, Odiseo cree estar en una tierra extraña y se preocupa inmediatamente por ocultar las riquezas que ha traído consigo del palacio de Alcínoo. En ese momento, aparece Atenea frente a él bajo la forma de un pastor de ovejas. Al verla, el hijo de Laertes la interroga y articula su primer engaño:

\begin{tabular}{|c|}
\hline 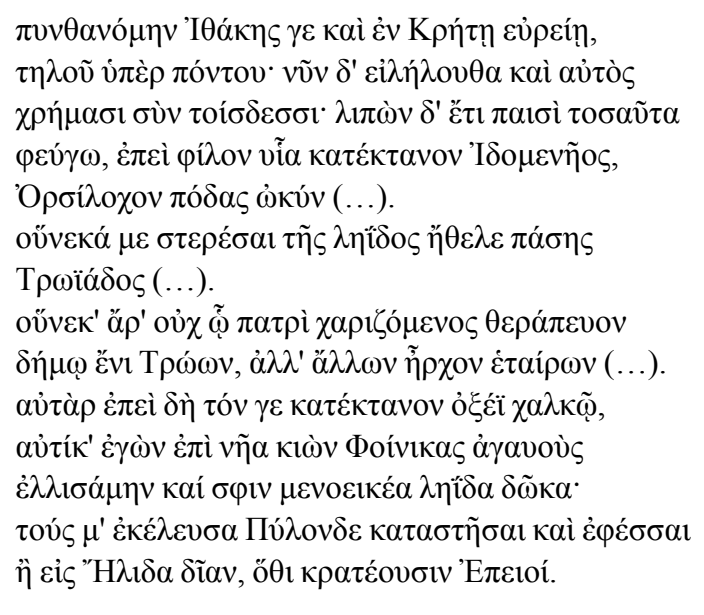 \\
\hline
\end{tabular}

${ }^{12}$ Cfr. un uso alternativo de esta frase en Hes. Th. 27. Allí el poeta la emplea para caracterizar la

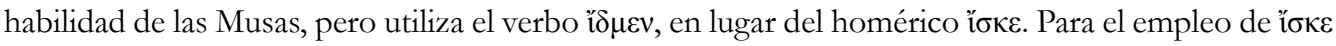
como una variante de Homero que otorga ambigüedad a la sintaxis, cfr. Russo et al. (1992: 87): "The misunderstanding of í $6 \kappa \varepsilon$ was encouraged by the ambiguous syntax of 203: do we construe ǐ $\sigma \kappa \varepsilon \psi \varepsilon \varepsilon v \delta \varepsilon \alpha$

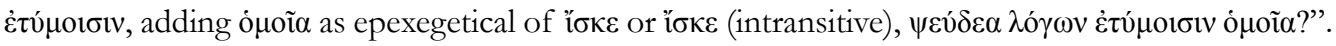

${ }^{13}$ Para otros motivos que justifican la elección de Creta, cfr. Tsagalis, (2012:314, n. 19). 


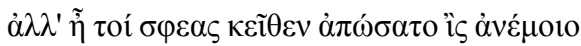

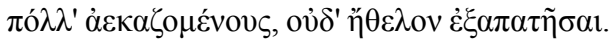
$\kappa \varepsilon i ̄ \theta \varepsilon v \delta \dot{\varepsilon} \pi \lambda \alpha \gamma \chi \theta \varepsilon \dot{v} \tau \varepsilon \zeta$ i

Oí hablar de Ítaca incluso en la ancha Creta muy lejos más allá del mar. Y ahora he llegado con estas riquezas. Dejando otras aún a mis hijos, huyo, porque maté al querido hijo de Idomeneo, a Orsíloco de rápido pie (...) porque quiso privarme de todo el botín de Troya (...) puesto que no servía dispuesto a su padre en el pueblo de los troyanos, sino que comandaba a otros compañeros (...). Después de que lo maté con el agudo bronce, al punto yendo hacia la nave de unos ilustres fenicios, les supliqué y les di abundante parte del botín. Pedí que ellos me condujesen a Pilos y me dejasen en la orilla o a la divina Élide, donde gobiernan los epeos. Pero ciertamente la fuerza del viento los arrojó de allí, muy en contra de su voluntad y no querían engañarme. Y errando desde aquel lugar llegamos aquí por la noche (Od.13. 256-278).

Este falso relato contiene algunos de los elementos ya señalados en 2 como parte de una Odisea alternativa: Creta, Idomeneo y una travesía con fenicios. Aquí el poeta individual opera sobre dichos elementos adecuándolos a su contexto e interlocutor inmediato. ${ }^{14}$ Así, la primera mentira cretense posee un carácter defensivo que deja traslucir el recelo y la desconfianza de Odiseo y articula (de manera un tanto indirecta) distintos mecanismos para asegurar que el pastor-Atenea no le cause daño ni a él ni a sus posesiones.

La figura de Idomeneo es central en la configuración de uno de estos mecanismos. En efecto, este héroe figura en el relato como padre de Orsíloco, personaje que ha sido asesinado a manos del mendigo-Odiseo ${ }^{15}$ por haberle querido robar el botín obtenido en Troya (vv. 259-262). A su vez, se aduce que dicho robo (y, por ende, el consecuente asesinato) habría sido producto de un supuesto conflicto entre el mendigo-Odiseo e Idomeneo durante la guerra de Troya (vv. 269-270). Así, la construcción de la relación entre el mendigo-Odiseo e Idomeneo en estos términos resulta provechosa para que el héroe deslice una velada advertencia al pastor-Atenea en su falso relato: "si intentas despojarme de mis riquezas en este momento como anteriormente lo hizo el hijo de Idomeneo, te mataré". ${ }^{16}$ Ahora bien, en caso de que una amenaza tan cruda no funcione, Odiseo incluye en su falsa narración otro motivo mediante el que intenta asegurar una buena recepción por parte del pastorAtenea. En esta oportunidad, el hijo de Laertes quiere "predicar con el ejemplo", para lo

\footnotetext{
${ }^{14}$ Algunos de los argumentos esbozados aquí (y en 3.3; 3.4; 3.5) con respecto a este tema ya fueron propuestos por Trahman (1952), pero bajo una premisa diferente. En efecto, dicho autor desestima por completo la existencia de una Odisea alternativa. Asimismo, no toma en consideración las reacciones de la audiencia frente a la performance.

${ }^{15}$ A partir de aquí se empleará el giro "mendigo-Odiseo" para indicar el accionar de Odiseo en tanto narrador y personaje ficticio de sus relatos, distinto al Odiseo "real" protagonista de la obra homónima. ${ }^{16}$ Para una lectura del asesinato de Orsíloco que plantea una analogía entre el personaje de Odiseo y Meríones con marcadas alusiones a la Dolonía iliádica, cfr. Haft (1984).
} 
cual emplea el estrato fenicio de una Odisea alternativa. En efecto, aquí los fenicios son

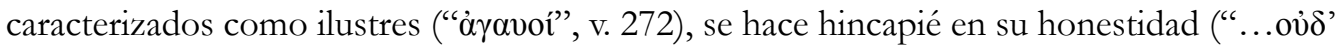

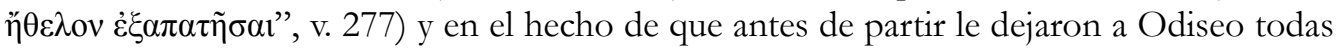

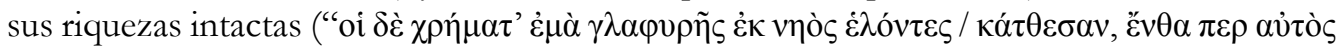

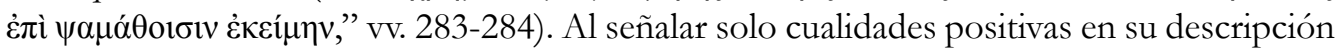
del obrar de los fenicios, el héroe parece querer decirle subrepticiamente al pastor-Atenea: "sé como los fenicios. No me engañes y no robes mis posesiones".

Asimismo, la configuración de la saga cretense en términos de una mentira le permite al poeta jugar con las expectativas y los conocimientos de la audiencia en cada narración. En el caso del relato destinado al pastor-Atenea, se dan similitudes y diferencias con respecto al episodio de Eumeo (cfr. 3.1 y 3.3). En ambas instancias, el auditorio es consciente de la falsedad del relato de Odiseo. No obstante, aquí la audiencia recibe la narración de Odiseo de un modo análogo al experimentado por el pastor-Atenea, puesto que tanto diosa como auditorio conocen la verdadera identidad del héroe. ¿Acaso esta identificación generaría en el público una reacción semejante a la de Atenea tras escuchar el relato de Odiseo? (cfr. 3.1). De ser así, dicha coincidencia de opiniones ocasionaría un particular goce durante la performance.

\subsection{ENCUENTRo CON EUMEO}

El segundo relato cretense tiene lugar en un contexto completamente diferente. En este caso, Odiseo se encuentra en la cabaña del porquerizo Eumeo y su mentira tiene por objetivo encubrir su identidad, no ya a un desconocido amenazador, sino a un querido sirviente que conoce de toda la vida. Esta circunstancia determina que el poeta construya el relato con no menores variaciones. En primer lugar se pueden considerar todos aquellos cambios que contribuyen a generar empatía entre Eumeo y Odiseo. Aquí algunos de los hitos de una Odisea alternativa son dispuestos de modo tal que se construya un fuerte vínculo entre ambos personajes. Se destacan dos: el origen cretense y las travesías en compañía de fenicios y tesprotos. ${ }^{17}$ Con respecto al origen cretense, se debe recordar que, en la narración dirigida a Atenea, Creta era caracterizada como la tierra de la que el héroe había sido desterrado. Aquí, en cambio, la isla aparece como un escenario de una infancia y una juventud bastante placenteras. En palabras de Odiseo-mendigo:

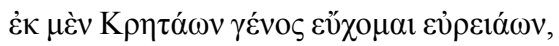

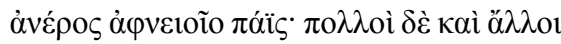

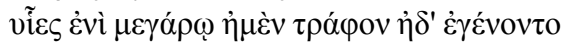

\footnotetext{
${ }^{17}$ Otros hitos pertenecientes a una Odisea alternativa que figuran en esta segunda mentira son la aparición de la figura de Idomeneo y el relato de las aventuras en Egipto. Aquí no se caracteriza a

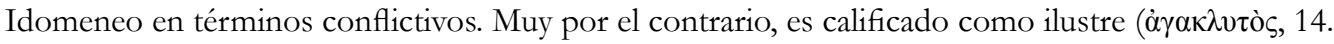
238) y al figurar Odiseo-mendigo como un colega suyo en el marco de la expedición a Troya aparece en el relato otro detalle positivo con el que asegurar el favor de Eumeo. Con respecto a las aventuras egipcias, cfr. 3.4.
} 


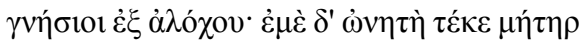

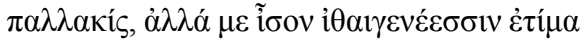

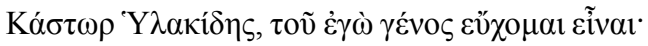

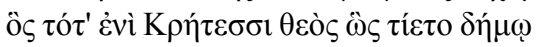

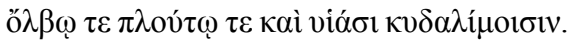

Declaro mi estirpe de la espaciosa Creta, el hijo de un rico varón. Otros muchos hijos se criaron conmigo en el palacio y nacieron de su legítima esposa. Y a mí me engendró una mujer comprada, su concubina. Pero me estimaba de igual modo que a los legítimos Cástor Hilácida, de cuya estirpe yo me jacto de ser, el que entonces era honrado como un dios en el pueblo por los cretenses a causa de su dicha y de su riqueza y de sus gloriosos hijos (14. 199-207).

Compárese esta caracterización con las circunstancias reales de la infancia de Eumeo, que este personaje relata en 15.403-484:

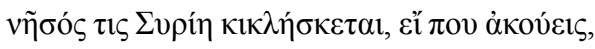

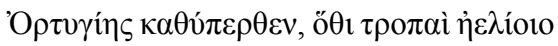

(...)

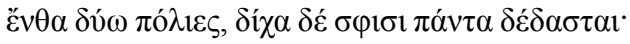

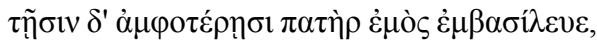

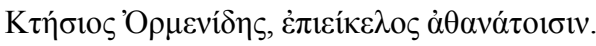

Hay una isla que se llama Siria-si acaso oyes-más allá de Ortigia, donde están los giros del sol (...) Allí existen dos ciudades y entre las dos se han repartido todas las cosas. En ambas reinaba mi padre, Ctesio Orménida, semejante a los inmortales (15. 403-414).

En ambos relatos se destaca la presencia de una figura paterna positiva que goza de cierto vínculo con el ámbito inmortal, ya porque es honrada como un dios, ya porque es semejante a ellos. Por otro lado, en la narración dirigida a Atenea no se incluía ninguna mención de la estirpe, detalle completamente innecesario considerando la intención con la que Odiseo le refirió la mentira a la diosa-pastor.

Las travesías en compañía de fenicios y tesprotos que figuran en la narración falsa del hijo de Laertes remiten, a su vez, a los viajes experimentados por Eumeo una vez secuestrado de su patria. Tanto Odiseo-mendigo como el porquerizo se enfrentaron a la esclavitud a causa de estos pueblos. Así, en el caso del primero, un varón fenicio diestro en engaños,

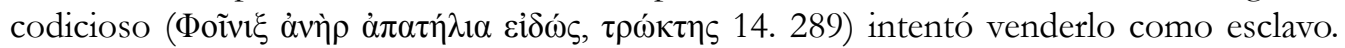
Luego, los marineros tesprotos que lo estaban conduciendo a Duliquio también tomaron

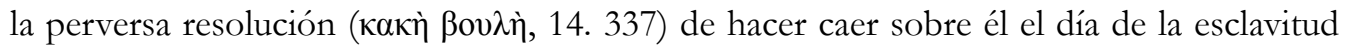

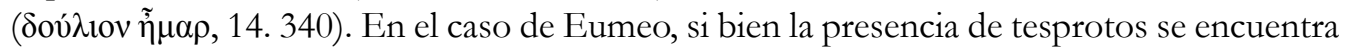
ausente, los fenicios que lo abducen también son caracterizados como codiciosos ( $\tau \rho \tilde{\omega} \kappa \tau \alpha 1$, 15. 416) y aparecen como los responsables de que el porquerizo haya llegado a Ítaca, donde fue comprado por Laertes. De igual modo, nótese la caracterización diametralmente opuesta 
de los fenicios en este relato falso de Odiseo y en el dirigido a Atenea. Mientras que allí este pueblo era descripto con atributos positivos (cfr. 3.2), aquí es calificado de manera negativa. Esta circunstancia constituye, quizás, uno de los ejemplos más evidentes que presenta el poeta de adecuación de un núcleo alternativo de nóstoi a su auditorio inmediato. En efecto, atribuirle a los fenicios una actitud favorable iría en detrimento de uno de los objetivos principales que encierra el relato falso dirigido a Eumeo, esto es, generar empatía y asegurar una buena recepción por parte del porquerizo.

Otra diferencia no menor entre el intercambio con Atenea-pastor y el falso relato dirigido a Eumeo es la introducción en este último del personaje de Odiseo. En efecto, durante el transcurso de la narración, Odiseo-mendigo le asegura al porquerizo:

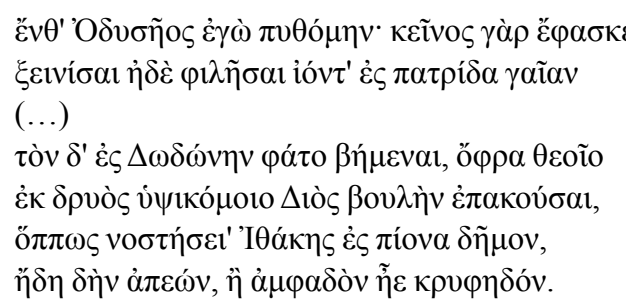

Allí [en Tesprotia] yo oí hablar de Odiseo. Pues aquél [el rey Eidón] me dijo que lo estaba hospedando y lo trataba con amabilidad a él, que volvía hacia la tierra patria. Y dijo que este iba a ir a Dodona para escuchar de la alta encina el designio de Zeus, cómo regresaría hacia el rico territorio de Ítaca, del que estaba ausente hacía mucho tiempo, si abiertamente o a escondidas (14. 322-332).

Esta referencia a la estancia de Odiseo en Tesprotia y su posterior consulta al oráculo de Dodona han sido identificadas por Tsagalis (cfr. 2) como estratos pertenecientes a una Odisea alternativa, probablemente una Thesprotia perdida de marcada impronta local, circunstancia avalada por la mención del santuario de Dodona. No obstante, nótese que el poeta no introdujo esta versión alternativa en el relato falso que Odiseo-mendigo le refirió a Atenea-pastor. Una vez más la elección y adaptación del material se encuentra condicionada por los objetivos del poeta (y de Odiseo) frente a su auditorio inmediato. En el caso del encuentro con la diosa disfrazada de extraño, era conveniente que la verdadera identidad de Odiseo permaneciese oculta. Aquí, en cambio, el rey de Ítaca introduce en el relato falso información acerca de su propio regreso quizás para indicar a Eumeo subrepticiamente que este no se encuentra frente a un desconocido, sino frente a su propio amo. La pregunta al oráculo de Dodona resulta de particular importancia en este sentido, puesto que concierne el modo en el que Odiseo ha de regresar a Ítaca, ya abiertamente, ya oculto. Sin embargo, tal como se estableció con anterioridad (cfr. 3.1), Eumeo hace caso omiso de las "pistas" que el hijo de Laertes va colocando para él durante la narración.

La introducción de la figura de Odiseo en el relato falso también podría haber generado una reacción particular en la audiencia de la performance. A diferencia de lo que ocurría en la primera de las mentiras, aquí el auditorio no recibe la información falsa 
de un modo análogo al de Eumeo, sencillamente debido al hecho de que ellos conocen la verdadera identidad de Odiseo y el porquerizo no. Esta obviedad, no obstante, quizás haya dejado al auditorio expectante durante la última parte de la narración y ansioso por saber si el porquerizo, interpretando las señales que Odiseo-mendigo va dejando durante el relato, lo reconocerá cuando finalice. Esto no sucede y la audiencia debe esperar un poco más aún para que la cadena de anagnöríseis que desembocará en la muerte de los pretendientes tenga lugar (cfr. 3.1).

\subsection{Encuentro con Antínoo}

El intercambio entre Odiseo-mendigo y Antínoo, uno de los pretendientes, tiene lugar en el palacio del hijo de Laertes. Allí, el héroe disfrazado le pide a Antínoo algo de comer y articula el siguiente discurso:

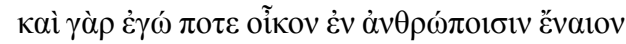

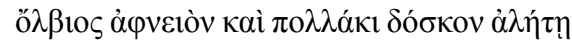

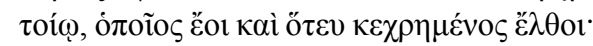

(..)

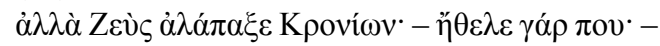

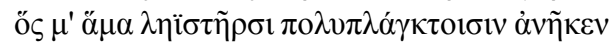

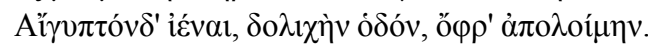

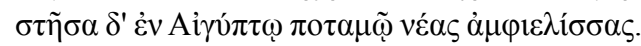

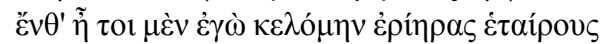

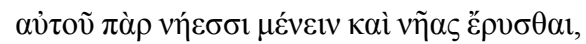

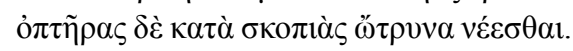

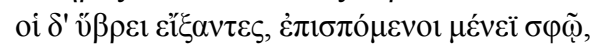

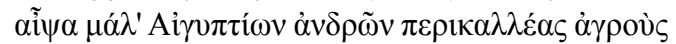

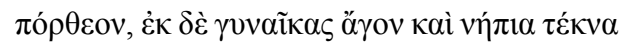

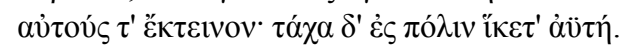

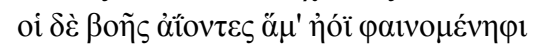

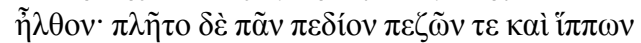

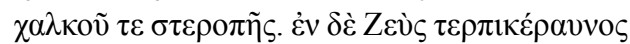

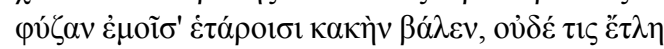

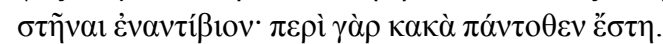

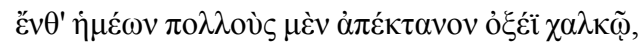

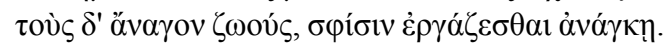

Pues yo también antaño habité dichoso una rica morada entre los hombres y muchas veces di al vagabundo, cualquiera que fuese y viniese necesitado de cualquier cosa (...) Pero Zeus Crónida me arruinó-pues acaso lo quiso-el que una vez me incitó a ir a Egipto con errabundos piratas, largo camino para destruirme. Detuve en el río Egipto las curvas naves. Entonces yo ordené que los fieles compañeros permanecieran junto a las naves y que custodiaran las naves e insté a espías a ir hacia puestos de observación. Pero ellos, cediendo a la violencia, siguiendo 
su propio impulso, destruyeron al punto los hermosos campos de los varones egipcios y se llevaban de allí a las mujeres e insensatos niños y mataban a los hombres. Rápidamente llegó el clamor a la ciudad. Y ellos, oyendo el griterío, vinieron al salir el sol. Y toda la llanura se llenó de infantería y también de jinetes y de reluciente bronce. Y Zeus que se deleita con el rayo arrojó a mis compañeros la maldita fuga y ninguno soportó estar en pie contra el enemigo. Pues los males se levantaban por todas partes. Allí mataron con el agudo bronce a muchos de los nuestros y a otros los condujeron vivos para trabajar por la fuerza para ellos (17.419-441).

En este relato se recupera una parte de la narración dirigida a Eumeo, esto es, las aventuras ocurridas en Egipto. En efecto, los versos 17.428-441 son idénticos a 14.259-272, circunstancia que no resulta sorprendente si se piensa que lo ocurrido en Egipto formaba parte de los hitos de una Odisea alternativa recogidos por el poeta de la obra homérica. No obstante, una vez más, esta repetición no constituye un mero Zitat épico, sino que se adecua al auditorio inmediato. Aquí, el poeta ha seleccionado de entre todo el material disponible la narración oral egipcia para que Odiseo-mendigo le deslice una amenaza a Antínoo. Asimismo, omite de ella las partes que no resultan funcionales para tal objetivo. En el caso de la mentira dirigida a Eumeo, luego de la referencia al trabajo forzado de los compañeros de expedición $(14.272=17.441)$, la narración explica con lujo de detalles cómo Odiseo-mendigo se arrojó a las rodillas del rey de Egipto para suplicar por su vida y cómo este lo protegió,

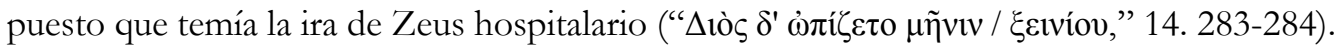
La referencia a la acogida favorable del rey y la mención de Zeus hospitalario se relacionan directamente con la actitud que ha tenido el porquerizo para con Odiseo-mendigo. Eumeo, a la usanza del rey de Egipto, le ha ofrecido cobijo en su choza y, por ende, no debe temer la cólera de los dioses.

En el intercambio con Antínoo, el narrador se concentra, por el contrario, tan solo en la parte trágica de los acontecimientos egipcios. En este sentido, resulta de gran

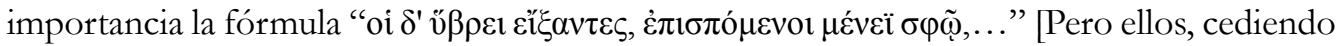
a la violencia, siguiendo su propio impulso...], empleada para describir el accionar de los compañeros de Odiseo-mendigo, puesto que también caracteriza con exactitud el modo en el que los pretendientes derrochan los bienes del hijo de Laertes. ${ }^{18}$ Asimismo, el argumento general del relato resulta sumamente adecuado para que Odiseo le deslice a Antínoo una amenaza encubierta: "así como los egipcios masacraron a mis compañeros a causa de sus excesos, así también te voy a asesinar yo por los tuyos."

Si se consideran una vez más las posibles reacciones de la audiencia, aquí, tal como ocurría en el caso de Eumeo, el auditorio conoce la verdadera identidad de Odiseo, mientras que Antínoo la ignora. No obstante, y a diferencia de lo que sucedía en el intercambio con

\footnotetext{
${ }^{18}$ Comportamientos análogos también se pueden percibir en los compañeros que siguieron a Odiseo durante los viajes relatados en la corte del rey Alcínoo, muy especialmente el episodio de las vacas del sol (1.6-9; 12. 260-419) y el enfrentamiento contra los Cícones (9. 43-45).
} 
el porquerizo, el hincapié no estaría puesto tanto en la generación de expectativas en torno a la anagnórisis inmediata de Odiseo (ya que la audiencia sabe que ser reconocido en ese momento por Antínoo es contraproducente para sus planes de venganza), sino quizás en una suerte de disfrute anticipatorio articulado mediante pensamientos del tipo: "Antínoo está maltratando al mendigo-Odiseo y haciendo caso omiso de su relato, sin saber que pronto le ocurrirá lo mismo que le sucedió a los compañeros en dicha narración."19

\subsection{Encuentro con Penélope}

El relato falso dirigido a Penélope tiene lugar en 19. 165-202, 221-248, 262-303 y presenta, igual que los otros, varios hitos pertenecientes a una Odisea alternativa. En este caso, el poeta ha seleccionado la mención de Creta, la figura de Idomeneo y la estancia en Tesprotia. La narración comienza estableciendo la patria y la estirpe de Odiseo-mendigo, tal como ocurría en el relato dirigido a Eumeo:

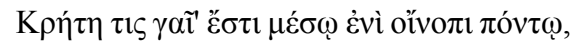

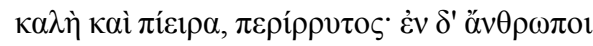

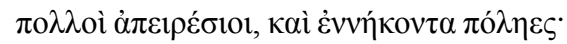
$(\ldots)$

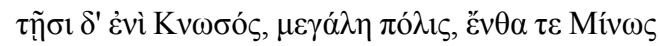

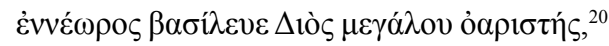

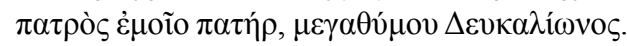

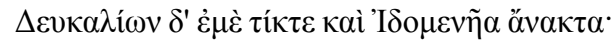

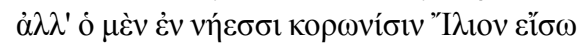

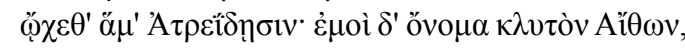

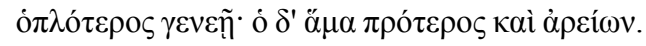

Existe una tierra en medio del vinoso ponto, Creta, hermosa y fértil, rodeada de mar. Y allí hay muchos, innumerables hombres y noventa ciudades. Y entre ellas Cnoso, gran ciudad, donde Minos, amigo del gran Zeus, reinó por nueve años, padre de mi padre, del magnánimo Deucalión. Y Deucalión me engendró a mí y al soberano Idomeneo. Y este fue a Ilión en las curvas naves junto con los Atridas. Mi ilustre nombre es Etón, el más joven para la estirpe. Pues aquél es el primero y el mejor ${ }^{21}(19.172-185)$.

\footnotetext{
${ }^{19}$ Nótese a este respecto que Antínoo es el único pretendiente que no ofrece nada de comer y de beber a Odiseo-mendigo. Aún más, le arroja un escabel para hacerlo caer (17. 462-467). Asimismo, también es el único que muere sin saber la verdadera identidad de Odiseo (22. 9-33).

${ }^{20}$ Para los significados que encierra el término ỏ $\alpha$ sı agonístico de igual a igual entre un hombre y una mujer, circunstancia que se adecúa por completo al presente intercambio dialógico entre Odiseo y Penelópe, cfr. Levaniouk (2010: 82-92).

${ }^{21}$ Para una explicación de la caracterización de Odiseo como hermano menor en términos de un ritual de pasaje que el héroe debe experimentar al llegar a Ítaca, cfr. Levaniouk (2010: 56-81).
} 
A partir de estas palabras, se puede constatar que solo en el caso de hallarse el mendigo-Odiseo frente a una persona querida, se opta por un desarrollo detallado de su ascendencia. No obstante, entre el linaje presentado a Eumeo y el dirigido a Penélope también existen significativas diferencias. Aquí, Odiseo no se caracteriza simplemente como el hijo de una concubina y de un varón rico, favorecido por su pueblo, sino que va un paso más allá y se atribuye un parentesco con uno de los soberanos más célebres de la leyenda cretense: el rey Minos. En este movimiento, la figura de Idomeneo resulta operativa para reforzar el estatus noble de Odiseo-mendigo, llamado aquí Etón. ${ }^{22}$ En este sentido, y a diferencia de lo que sucedía en el encuentro con Atenea, Idomeneo ingresa a la última mentira cretense bajo un cariz netamente positivo. Ahora bien, ¿por qué tienen lugar estas modificaciones? Una vez más la respuesta a este interrogante está dada por el carácter del auditorio inmediato de Odiseo-mendigo, es decir, Penélope. Aquí el narrador no se encuentra hablando con un sirviente, sino con una mujer noble. ${ }^{23}$ Así, se atribuye en la construcción de su falsa identidad un estatus social semejante (e incluso superior) al que detenta la reina de Ítaca, quizás con el objetivo de provocar su admiración o de generar un clima de confianza para el intercambio. En efecto, según Levaniouk (2010: 52-53):

It is worth emphasizing the loftiness of the lineage Aithon claims for himself, since it makes for such an astonishing statement in the mouth of a beggar (...) He begins his conversation with Penelope with a performance of the "ruler's truth," showing that he knows what a real king is and has mastered the discourse characteristic of such a king. He then expands on this veiled demonstration of his identity by making a direct claim to belong not simply to a royal lineage, but to an exalted royal lineage with a special claim to Zeus's support.

Otro patrón que el poeta repite en su configuración de las mentiras cretenses dirigidas a Eumeo y Penélope es la introducción de la figura de Odiseo en el falso relato. No obstante

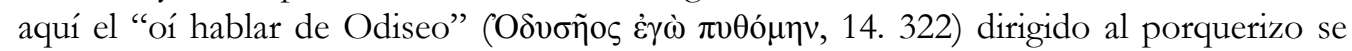

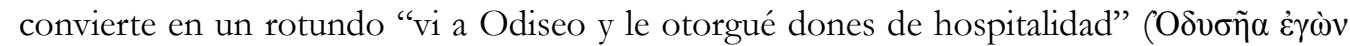

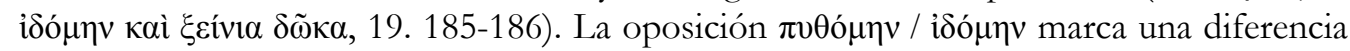
fundamental en el grado de conocimiento que el falso narrador tiene de Odiseo en ambos relatos. En el caso del intercambio con Penélope, la llegada inminente de Odiseo se hace acaso más tangible al plantearse allí un encuentro directo entre Etón y el legítimo rey de Ítaca. En otras palabras, las "pistas" que el esposo de Penélope introduce en este relato son

\footnotetext{
${ }^{22}$ Para un análisis de la elección de este nombre efectuada por Odiseo, cfr. Levaniouk (2010: 36-49). Allí esta autora explicita las vinculaciones entre el nombre Etón, en griego Aï $\theta \omega v$, y las connotaciones que dicho nombre conlleva aplicado a la figura del rey de Ítaca. En efecto, el vocablo hace alusión a características tales como el hambre y la astucia, todos atributos que caracterizan de manera adecuada al mendigo Odiseo.

${ }^{23}$ Para un análisis de los modos en los que el poeta introduce interlocutores de distintos estratos sociales en las mentiras cretenses con el objetivo de incluir a una audiencia que también exhibe marcadas diferencias sociales, cfr. Doherty (1994).
} 
de carácter más evidente que aquellas dirigidas al porquerizo. ${ }^{24}$ Asimismo, esta circunstancia modifica nuevamente el tratamiento de Creta. Aquí la isla ya no es ni el lugar del destierro ni el escenario de una infancia y una juventud felices, sino principalmente el paraje en el que Etón recibe a Odiseo.

Otro estrato oral recuperado por el poeta en la configuración del relato a Penélope es la estancia en Tesprotia y la consulta al oráculo de Dodona. Efectivamente, los versos 19. 287-293, 293-300 son idénticos respectivamente a 14. 332-336, 324-332 y su introducción aquí cumple funciones análogas a las descriptas en 3.3. No obstante, en este caso, dichas funciones se ven complementadas por la aseveración:

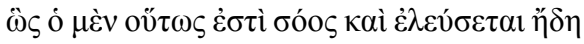

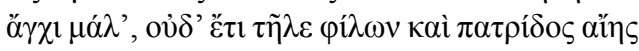

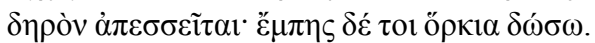

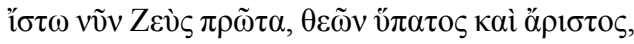

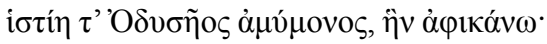

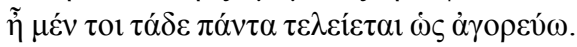

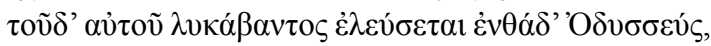

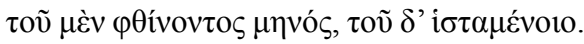

Así este está a salvo y ahora vendrá cerca, pues ya no permanecerá alejado mucho tiempo de sus amigos y de su patria tierra. Y en verdad sobre esto prestaré juramento: que sea ahora primero testigo Zeus, el más alto y noble de los dioses, y el hogar irreprochable de Odiseo, al que llego: ciertamente todas las cosas se cumplirán como lo digo. Y Odiseo regresará aquí este mismo año, ${ }^{25}$ consumido este mes y comenzado el siguiente (19.300-307).

En el caso del relato de Eumeo, la narración concluía con una referencia a la esclavitud a la que había sido sometido Odiseo-mendigo en manos de los tesprotos, circunstancia que servía para generar empatía entre este y el porquerizo. Aquí, en cambio, la falsa mentira cretense concluye con una afirmación aún más radical del inminente regreso de Odiseo al hogar. De este modo, existe en la narración dirigida a Penélope una voluntad mucho más marcada de aseverar el retorno de Odiseo que la que se halla en el intercambio con Eumeo. Esta circunstancia podría deberse al modo en el que el poeta construye la relación entre Odiseo y Penélope a lo largo de los últimos cantos del poema. En efecto, existe en estos cantos una tensión narrativa en torno al interrogante "¿reconoce Penélope a su marido antes de su reencuentro oficial en el canto 23 de la Odisea?" que hace que esta pregunta no pueda

\footnotetext{
${ }^{24}$ A estas "pistas" se podrían añadir la instancia en la que Odiseo-mendigo, a pedido de Penélope, describe la vestimenta de su esposo con total exactitud (19.225-235) y la inclusión en el relato dirigido a la hija de Icario de sucesos que realmente le acontecieron a Odiseo, tales como el episodio de las vacas del sol y su permanencia en la corte de los feacios (19. 274- 282).

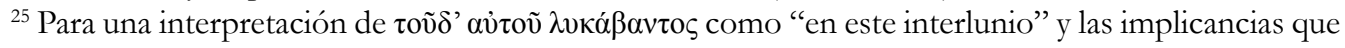
tal interpretación conlleva, cfr. Austin (1975: 239- 253).
} 
responderse con certeza ni afirmativa ni negativamente. ${ }^{26}$ Quizás la aseveración marcada del retorno de Odiseo en esta mentira cretense podría considerarse un nuevo elemento que contribuye a generar dicha tensión.

Con respecto a la audiencia, sus sensaciones serían semejantes a las descriptas para el relato dirigido a Eumeo (cfr. 3.3). Nótese que Penélope también dice no creer en el retorno de su esposo a pesar de las palabras del mendigo-Odiseo (19. 309-317). No obstante, si se acepta el planteo expuesto arriba, el auditorio esperaría la anagnórisis definitiva entre Odiseo y Penélope atravesado por interrogantes y tensiones que se encuentran ausentes del modo en el que el poeta construye el reencuentro entre el hijo de Laertes y el porquerizo. En efecto, a pesar de la negativa exhibida por Penélope frente al regreso de su esposo, el poeta introduce a lo largo del canto 19 ciertas escenas que hacen creer que ella ya ha reconocido a Odiseo. Estas escenas son, respectivamente, el episodio del sueño de los gansos (19. 535-550), el discurso sobre las puertas de cuerno(s) y marfil (19. 560-569) y la propuesta del desafío del arco (19. 570-581). En el caso de la primera escena, el sueño adquiere un estatus profético en boca de Penélope y hace las veces de "covert test of Odysseus, an invitation to confirm his wife's thoughts and plans. Penelope conveys to the beggar that if he is indeed Odysseus then her despair will turn into a triumph over the suitors" (Levaniouk, 2010: 240). El discurso sobre las puertas de cuerno(s) y marfil y la propuesta del desafío del arco persiguen objetivos análogos. En efecto, mediante estas maniobras, la reina de Ítaca parecería probar al mendigo- Odiseo, sospechando encontrarse ya frente a su marido.

\section{Conclusiones}

En este trabajo se han analizado los relatos cretenses de Odiseo bajo una premisa semejante a la establecida por Finkelberg (cfr. 1) para la concepción de las fórmulas homéricas. Así, se ha asumido la existencia de una Odisea alternativa integrada por estratos tales como viajes a Creta, presencia de Idomeneo, batalla en Egipto, viajes con fenicios y tesprotos, que el poeta emplearía en la configuración de estas narraciones falsas. Sin embargo, se ha objetado su concepción como un mero Zitat incorporado a la Odisea homérica, arguyendo que el poeta individual opera sobre ella mediante mecanismos compositivos propios. Estos mecanismos compositivos se evidencian muy especialmente cuando se considera la presencia del auditorio interno del falso relato. Así, el poeta adecua el contenido de las mentiras cretenses a las intenciones que tiene o a los sentimientos que desea provocar el personaje de Odiseo en el marco de dicho auditorio. Por otro lado, hacer ingresar la tradición oral de una Odisea alternativa a la obra homérica bajo el estatus de una mentira le permite al poeta jugar con los conocimientos de la audiencia de la performance. Dichos conocimientos también provocan reacciones particulares en cada contexto, que van desde un guiño cómplice entre el auditorio y Atenea-pastor hasta la generación de expectativas en torno a las distintas anagnöríseis que presenta el poema.

${ }^{26}$ Cfr. Harsh (1950); Amory (1963); Russo (1982); Winkler (1990); Scodel (2001); Heitman (2005); Vlahos (2011); Louden (2011); Reece (2011); Levaniouk (2010), entre otros. 


\section{REFERENCIAS}

AMORY, Anne. The Reunion of Odysseus and Penelope. En: TAYLOR, Charles Henry (Ed.). Essays on the Odyssey. Selected Modern Criticism. Bloomington: University of Indiana Press, 1963, p. 100-136.

AUSTIN, Norman. Archery at the Dark of the Moon: Poetic Problems in Homer's Odyssey. Berkeley: University of California Press, 1975.

DANEK, Georg. Epos und Zitat. Studien zu den Quellen der Odyssee. Viena: Verlag der österreichischen Akademie der Wissenschaften, 1998.

DOHERTY, Lilian. Performance Dynamics and the Internal Audiences of the Odyssey: disponible en: <https://www.didaskalia.net/issues/vol3no3/doherty.html>. Consultado el: 21 Abril 2018.

EMLYN-JONES, Chris. "True and Lying Tales in the 'Odyssey". The Classical Association, v. 33, n. 1, p. 1-10, Apr. 1986.

FINKELBERG, Marguerite. Oral formulaic tradition and the individual poet. In: MONTANARI, Franco; RENGAKOS, Antonios; TSAGALIS, Christos (Ed.). Homeric Contexts: Neoanalysis and the Interpretation of Oral Poetry. Berlin; Boston: De Gruyter, 2012, p. $73-82$.

FOLEY, John Miles. The Theory of Oral Composition: History and Methodology. Bloomington: Indiana University Press, 1988.

FOLEY, John Miles. Traditional Oral Epic: The Odyssey, Beowulf, and the Serbo-Croatian Return Song. Berkeley: University of California Press, 1990.

FOLEY, John Miles. Homer's Traditional Art. University Park: Pennsylvania State University Press, 1999.

HAFT, Adele. Odysseus, Idomeneus and Meriones: The Cretan Lies of "Odyssey" 13-19. The Classical Journal, v. 79, n. 4, p. 289-306, Apr.-May 1984.

HARSH, Philip. Penelope and Odysseus in Odyssey XIX. The American Journal of Philology, v. 71, p. 1-20, 1950.

HEITMAN, Richard. Taking Her Seriously: Penelope \& the Plot of Homer's Odyssey. Ann Arbor: University of Michigan Press, 2005.

LEVANIOUK, Olga. Eve of the Festival: Making Myth in Odyssey 19. Hellenic Studies 46. Washington, DC: Center for Hellenic Studies, Trustees for Harvard University, 2010.

LORD, Albert. Homer and Huso II. Narrative Inconsistencies in Greek and Southslavic Heroic Song. Transactions of the American Philological Association, v. 69, p. 439-445, 1938.

LORD, Albert. The Singer of Tales. Cambridge MA: Cambridge University Press, 1960.

LORD, Albert. Epic Singers and Oral Tradition. London: Cornell University Press, 1991.

LOUDEN, Bruce. Is There Early Recognition between Penelope and Odysseus?: Book 19 in the Larger Context of the 'Odyssey'. Classical Literature, v. 38, p. 76-100, March 2011. 
NAGY, Gregory. The Best of the Achaeans: Concepts of the Hero in Archaic Greek Poetry. Baltimore: the John Hopkins University Press, 1979.

NAGY, Gregory. Homeric Questions. Texas: University of Texas Press, 1996.

NOTOPOULOS, James. Studies in Early Greek Oral Poetry. Harvard Studies in Classical Philology, v. 68, p. 1-77, 1964.

PARRY, Milman. The Making of Homeric Verse: The Collected Papers of Milman Parry. In: PARRY, Adam (Ed.). Oxford: Oxford University Press, 1971.

REECE, Steve. Penelope’s 'Early Recognition' of Odysseus from a Neoanalytic and Oral Perspective. Classical Literature, v. 38, p. 101-117, March 2011.

REECE, Steve. The Cretan Odyssey: A Lie Truer Than Truth. The American Journal of Philology, v. 115, n. 2, p. 157-173, Summer 1994.

RICHARDSON, Scott. Truth in the Tales of the "Odyssey". Mnemosyne, v. 49, n. 4, p. 393402, Sep. 1996.

RUSSO, Joseph. Interview and Aftermath: Dream, Fantasy, and Intuition in Odyssey 19 and 20. The American Journal of Philology, v. 103, p. 4-18, 1982.

RUSSO, Joseph; FERNÁNDEZ GALIANO, Manuel; HEUBECK, Alfred (Ed.). A Commentary on Homer's Odyssey III. Books XVII-XXIV. Oxford: Oxford Clarendon Press, 1992.

SCODEL, Ruth. The Suitors' Games. The American Journal of Philology, v.122, p. 307-327, 2001.

STALLBAUM, Gottfried. (Ed.). (Parekbolaí) Eustathii Archiepiscopi Thessalonicensis: Commentarii ad Homeri Odyssea. Leipzig: Weigel, 1826. v. II.

TRAHMAN, Carl. Odysseus’ Lies (“Odyssey”, Books 13-19). Phoenix, v. 6, n. 2, p. 31-43, Summer 1952.

TSAGALIS, Christos. Deautorizing the Epic Cycle: Odysseus' False Tale to Eumaeus (Od.14.199-359). En: MONTANARI, Franco; RENGAKOS, Antonios; TSAGALIS, Christos (Ed.). Homeric Contexts: Neoanalysis and the Interpretation of Oral Poetry. Berlin/Boston: De Gruyter, 201. p. 309-346.

VLAHOS, John. Homer's 'Odyssey': Penelope and The Case for Early Recognition. Classical Literature, v. 38, p. 1-75, March 2011.

VON DER MÜHLL, Peter (Ed.). Homeri Odyssea. Basilea: Helbing \& Lichtenhahn, 1964.

WEST, Stephahnie. An alternative Nostos for Odysseus. Liverpool Classical 6, p. 169-175, Monthly, 1981.

WINKLER, John. Penelope's Cunning and Homer's. In: WINKLER, John (Ed.). The Constraints of Desire: The Anthropology of Sex and Gender in Ancient Greece. New York: Routledge, 1990. p. 129-161.

WOODHOUSE, William John. The Composition of Homer's Odyssey. Oxford: Oxford University Press, 1930. 